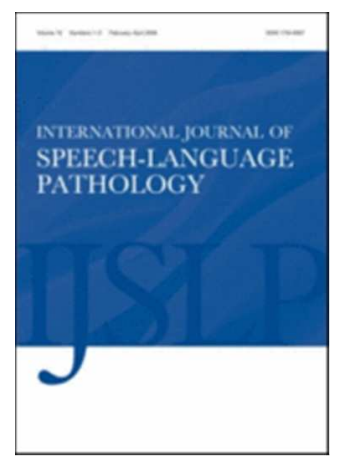

\title{
A SYSTEMATIC REVIEW OF RESONANT VOICE THERAPY
}

\begin{tabular}{|r|l|}
\hline Journal: & International Journal of Speech-Language Pathology \\
\hline Manuscript ID & TASL-2015-0171.R2 \\
\hline Manuscript Type: & Original Paper \\
\hline Keywords: & Dysphonia, Voice, Voice disorder \\
\hline
\end{tabular}

SCHOLARONE ${ }^{\text {m }}$

Manuscripts 


\title{
A SYSTEMATIC REVIEW OF RESONANT VOICE THERAPY
}

\author{
ABSTRACT \\ Purpose To systematically review the literature on resonant voice therapy and to \\ evaluate the level of evidence on the effectiveness of using resonant voice therapy in treating \\ dysphonia. \\ Method Refereed journal papers from 1974 to 2014 were retrieved and reviewed by \\ two independent reviewers using the keywords "Humming, Resonance, Resonant Voice, \\ Semi-occluded or closed tube phonation" using available database systems. Quality of \\ evidence was evaluated by using the Grading of Recommendations Assessment, \\ Development and Evaluation (GRADE).
}

Result Thirteen papers met the search criteria. Nine papers were selected by the two reviewers. Two of the papers were randomised-controlled studies and the other seven were observational studies. At least four types of resonant voice therapies were described. They included the Lessac-Madsen Resonant Voice Therapy, Y- Buzz, Resonance Therapy and Humming. The overall level of quality of evidence was graded as "moderate".

Conclusion There were limited studies that investigated the effectiveness of resonant voice therapy. Most studies were small-scale uncontrolled observational studies with the inclusion of only small samples or specific populations. There is clearly a need for more large-scale randomized controlled studies with a wider range of populations to provide further evidence on the effectiveness of resonant voice training. 


\section{INTRODUCTION}

Resonant voice is a common vocal facilitating treatment method used to treat voice problems (Boone, McFarlane \& Von Berg, 2005; Colton, Casper \& Leonard, 2006), specifically with individuals who have hyperfunctional or phonotraumatic voice disorders (Chen Hsiao, Hsiao, Chung, Chiang, 2007; Roy et al, 2003; Verdolini-Marston, Burke, Lessac, Glaze, Caldwell, 1995). It has been contended that resonant voice therapy aims at reducing the effect of vocal pathology by facilitating the production of a perceptually clear voice using relatively neutral or not over-adducted vocal folds during phonation (Verdolini-Marston et al, 1995; Verdolini, Druker, Palmer, \& Samawi, 1998). It has been postulated that resonant voice production maximises vocal output while minimising inter-vocal fold impact on vibration, thus minimising new injury (Roy et al, 2003; Stemple, Glaze, Klaben, 2000, Verdolini et al, 1995). Recently, there is evidence to suggest that resonant voice production facilitates vocal fold tissue healing more so than merely voice rest or spontaneous speech (Verdolini Abbott, Li, Branski, Rosen, Grillo, Steinhauer, \& Hebda, 2012).

\section{Physiology and aerodynamic of resonant voice}

In resonant voice production, the vocal folds are believed to be slightly adducted/abducted (neutral adduction with minimal force) during phonation (Verdolini-Marston et al, 1995; Verdolini et al, 1998; Peterson, Verdolini-Marston, Barkmeier, \& Hoffman, 1994). Therefore, the impact force between the two vocal folds would be minimised and thus reduce the exacerbation of existing vocal fold pathology (Boone et al, 2005; Colton et al, 2006; Verdolini et al, 1998). 
In a 2001 paper, Titze explained vocal fold vibration using the concept of 'inertance', which is "an acoustic property of an air mass (usually a column of air in a tube) being accelerated or decelerated by pressure" (p. 520). The inertive vocal tract facilitates the vibration of the vocal folds. Titze (2001) found that the ease of production and vocal fold vibration associated with resonant voice, is facilitated by a decrease in the phonation threshold pressure, which is the lowest subglottal pressure required to initiate and sustain vocal fold vibration. It was found that an increase in air column inertance would lead to a decrease in phonation threshold pressure (Titze, 2001). A decrease in the cross-sectional area or an increase in the length of the vocal tract would lead to an increase in air column inertance, thus facilitating an efficient voice production and vocal fold vibration associated with resonant voice (Titze, 2001).

Titze (2006) reconstructed vocal fold vibration during resonant voice production using a computer simulation model. The simulation showed the effects of epilarynx narrowing and a semi-occluded vocal tract during resonant voicing. The intensity of voice produced, the vocal fold impact force, and overall vocal economy during resonant voice production were investigated using the simulation model. Titze (2006) found that the maximum flow declination rate, which is associated with the voice output spectrum, occurred when the epilarynx tube was narrowed and the opening of the mouth was widened. Titze (2006) contended that in a properly produced resonant voice, the semi-occlusion of the vocal tract increases the interaction between the source (vocal fold vibration) and filter (the supralaryngeal resonance), therefore yielding a high vocal intensity, efficiency and economy.

Titze (2006) also found that the lowest maximum glottal area declination, which is associated with low impact between the vocal folds, occurred when the epilarynx tube was widened while the opening in mouth was narrow. The semi-occlusion at the mouth was believed to 
increase the back pressure, thus lowering the amplitude of the vocal fold vibration, collision velocity and subsequently lowering the impact force between the vocal folds. This allows building up of high pressure in the vocal tract without excessive damage to the tissues. It has been shown that the degree of the occlusion of the vocal tract would influence the amplitude of the vocal fold vibration (Guzman, Laukkanen, Krupa, Horacek, Svec, \& Geneid, 2013). It was argued that the semi-occlusion at the mouth provides a kinaesthetic sensation of the backpressure by the speaker (Titze, 2006). Therefore, semi-occlusion using the humming of $/ \mathrm{m} /$ is commonly used for resonant voice practice (Titze, 2006).

\section{Use of resonant voice in voice therapy}

The use of resonant voice as a therapeutic method for voice disorders has been documented in the literature. Resonant voice therapy focuses on the production of a strong and clear voice with the least effort. The production generally involves a "forward tone" with vibratory sensations on the alveolar ridge and the maxillary bones (Chen, Ma \& Yiu, 2014; Chen et al, 2007; Verdolini-Marsron et al, 1995).

The effects of resonant voice therapy on voice disorders have been investigated using different methodological approaches and a number of outcome measures. Outcome measures used included changes in auditory-perceptual voice quality improvement (Chen et al, 2007; Verdolini et al, 1995; Yiu \& Ho, 2002), in the acoustic output of voice changes (Chen et al, 2007; Titze, 2001; Yiu \& Ho, 2002), in vibrations in facial bones (Chen, Ma \& Yiu, 2014), in phonatory aerodynamic changes (Chen et al, 2007), in vocal fold vibratory pattern (Barrichelo \& Behlau, 2007; Chen et al, 2007), and in voice-related quality of life such as those assessed with Jacobson et al's (1997) Voice Handicap Index (Chen et al, 2007; Roy et al, 2003) and self-perceived voice severity by dysphonic individuals (Roy et al, 2003). 
Resonant voice therapy has been described using different names in the literature. It has been called Resonant Voice Therapy (Verdolini-Marston, 1995); Lessac-Madsen Resonant Voice therapy (LMRVT; Verdolini, 2000), Resonance Therapy (Stemple et al, 2000), Humming (Boone et al, 2005; Colton et al, 2006; Yiu \& Ho, 2002), and resonant voice based on Lessac's (1997) Y-Buzz (Barrichelo \& Behlau, 2007).

Lessac-Madsen Resonant Voice Therapy was promoted by K. Verdolini Abbott (Orbelo, Li, \& Verdolini Abbott, 2014; Verdolini, 2000) based on practices used to improve voice production (Peterson et al., 1994; Verdolini et al., 1998). It is shown that in resonant voice, an individual phonates with barely abducted vocal folds while proprioceptive feedback is provided through the kinaesthetic sensations on the alveolar ridge and the facial bones (Peterson et al., 1994; Verdolini et al., 1998).

The resonance therapy described by Stemple emphasizes on experiential and hierarchical practice (Stemple et al, 2000). The aim of the program is to provide a context through a hierarchy to facilitate resonant voice (Stemple et al, 2000). Proprioceptive feedback is given to the client by means of vibratory sensations on the anterior alveolar ridge or other facial areas (Stemple et al, 2000). Details of the therapeutic procedures based on these methods will be described in the Results section later.

Humming technique has been described in a number of classical voice textbooks (e.g. Boone et al, 2005; Colton et al, 2006). This technique involves the use of nasal consonants for practice (Colton et al, 2006). Therapy usually begins with the production of a "hum", as in acknowledging someone sincerely, at comfortable pitch with a gentle voice onset. The 
humming promotes a phonation with gentle voice onset and provides proprioceptive feedback through nasal and facial vibrations (Colton et al, 2006).

Barrichelo and Behlau (2007) reported the use of Y-Buzz, which is a combination of the consonant $\mathrm{Y}(/ \mathrm{j} /)$ and the long vowel /i:/, in improving the voice of actors. Barrichelo and Behlau (2007) developed this method based on the work of Arthur Lessac (1997). The method focuses on proprioceptive sensations of vibration on the alveolar ridge and the nasal bridge (Barrichelo \& Behlau, 2007; Lessac, 1997).

\section{Effects of resonant voice therapy}

The effects of resonant voice have been investigated by a number of researchers (Barrichelo \& Behlau, 2007; Chen et al, 2007; Chen, Ma \& Yiu, 2014; Ogawa et al, 2013, 2014; Roy et al, 2003; Verdolini et al, 1995; Verdolini et al, 1998; Yiu \& Ho, 2002). Different methodological approaches have been used. Two major approaches have been used in evaluating the effect of resonant voice therapy. One approach is concerned with the evaluation of the effectiveness of resonant voice therapy with individuals with dysphonia over a period of time (Chen et al., 2007; Chen, Ma \& Yiu, 2014; Roy et al, 2003; Verdolini et al, 1995; Yiu \& Ho, 2002), while the other approach has focused on the acoustic and physiological characteristics of resonant voice production (Barrichelo \& Behlau, 2007; Ogawa et al, 2013, 2014; Verdolini et al, 1998; Peterson et al, 1994). Studies also sampled different subject types for their investigations. Some of them recruited healthy individuals (Chen, Ma \& Yiu, 2014) or vocally trained actors and singers as subjects (Barrichelo \& Behlau, 2007; Verdolini et al, 1998), while others targeted specific disorder groups such as 
those with muscle tension dysphonia (Ogawa et al, 2013, 2014), or population groups such as teachers (Roy et, al, 2003) and women (Chen et al, 2007; Verdolini et al, 1995).

The present investigation aimed at providing a comprehensive review and summary of contemporary resonant voice therapy, to describe the contents of the different varieties of resonant voice therapy and the therapeutic steps involved. The review also includes an evaluation of the level of evidence of the effectiveness of using resonant voice therapy in treating vocal pathology.

\section{Systems for evaluating level of evidence}

In relation to the evaluation of the level of evidence, a number of grading systems are available in the literature for evaluating the level of evidence of health-related studies. They include the Consolidation Standards of Reporting Trials (CONSORT; Schulz, Altman, \& Moher, 2010), Strength of Recommendation Taxonomy (SORT; Ebell et al, 2004), U.S. Preventive Service Task Force (USPSTF; Barton et al, 2007) and the Grading of Recommendations, Assessment, Development and Evaluations (GRADE; Schünemann, Brozek, Guyatt, \& Oxman, 2013). The CONSORT provides a 25-item checklist guidance and a flow chart diagram for assessing the evidence of parallel-group randomized controlled trial (RCT) findings (Schulz et al, 2010). It is, however, neither a rating nor a ranking system. The SORT provides a structured procedure to rate individual studies or bodies of evidence using ratings 1, 2, or 3 according to quality, quantity and consistency of the evidence (Ebell et al, 2004). The SORT, however, does not distinguish between good or bad observational studies (Ebell et al, 2004). The USPSTF is designed to provide a standard way to evaluate the effects of a preventive service on health outcomes (Barton et al, 2007). This system assigns evidence to three levels: high, moderate and low, according to the certainty that the service 
provided will be beneficial to the clients (Barton et al, 2007). The GRADE system is an evidence grading system used by a wide range of organizations such as Cochrane collaboration and World Health Organization groups (Schünemann et al, 2013). GRADE grades the evidence into four levels: high, moderate, low and very low. The system also allows for upgrade or downgrade of the overall level of evidence by further reviewing a number of specific methodological factors (Schünemann et al, 2013).

It is generally agreed that well-implemented randomized controlled trials provide useful evidence. Nevertheless, observational studies may also provide important information especially when the number of studies with randomized controlled trials is limited (Barton et al, 2007). Therefore, an evidence rating system which covers the evaluation of observational studies would be necessary. The CONSORT system would not be appropriate since it is only used to report parallel-group randomized controlled trials (Schulz et al, 2010). SORT is a less comprehensive grading systems and it does not distinguish between good and bad observational studies (Ebell et al, 2004). Both the GRADE and USPSTF employ similar evaluation methods and also ascertain evidence from observational studies (Barton et al, 2007). The GRADE approach evaluates quality of evidence using four levels while the USPSTF uses three levels (Barton et al, 2007). The criteria used to evaluate evidence for GRADE are similar to that used by USPSTF (Barton et al, 2007). However, the GRADE system has been used in diagnostic, treatment and prevention studies while the USPSTF was designed primarily for prevention studies (Barton et al, 2007). Therefore, GRADE approach would be the most suitable evidence grading system for studies that include both randomized controlled and observational studies. 
Again, the objectives of this study were:

1) to provide a systematic review of the contents of different resonant voice therapy types in terms of definitions and the therapeutic steps involved;

2) to evaluate the level of evidence on the effectiveness of resonant voice therapy in treating individuals with vocal pathology.

\section{METHODOLOGY}

\section{Identifying published papers}

Papers published in peer-reviewed journals that reported the effects of resonant voice therapy between 1974 and 2014 were identified through a database search that included the Elsevier ScienceDirect Complete, Medline and Proquest Medical Library New Platform. Keywords used for searching included: "Forward Focus, Hum, Humming, Nasal Consonant, Nasal Resonance, Resonance, Resonance Therapy, Resonant Voice Therapy, Resonant Voice, Semi-occluded Vocal Tract, Closed Tube Phonation, and Effectiveness of Resonance Voice Therapy". Dissertations, theses, books, non-refereed articles were not included. Only journal papers published in English were reviewed. Two final year speech therapy students of the Division of Speech and Hearing Sciences, at The University of Hong Kong were involved in searching the published journal papers. The two reviewers conducted the search independently and came up with an initial LIST of papers based on scanning the title and the abstract of journal articles. The two reviewers then selected a SET of papers that satisfied the criteria of "studies that investigated resonant voice, resonance voice or humming. The fulltext of the journal papers selected as the SET were read in detail by the two reviewers independently. The two reviewers were asked to select a CORE of papers using the criteria "studies that investigated primarily the long term or immediate treatment effect". The selected papers should also report detailed therapeutic procedures and also quantitative 
outcome measures. These CORE papers were comprehensively reviewed to decide on a grading of quality of evidence subsequently. Any disagreements regarding the selection of CORE papers for comprehensive review were resolved by discussion and a consensus was achieved. The 27-point PRISMA guidelines (www.prismastatement.org) were used throughout for the selection and inclusion processes (Moher et al, 2009).

\section{Grading of quality of evidence}

The selected CORE papers were independently graded by the two reviewers according to the level of evidence using the GRADE system (Higgins \& Green, 2011). Evidence is classified into high, moderate, low or very low category based on the methodological design of the study. Randomized clinical trial would be given a high level of evidence rating while an observational study would be given a low level of evidence (see Table 1). The overall quality rating was then upgraded or downgraded, depending on a number of factors. The downgrading factors include 1) study limitations, 2) possible risks of bias, 3) indirectness of evidence, 4) discrepancies across studies without plausible explanations, 5) imprecision of results, and 6) suspicion of publication bias. Factors to be included for possible upgrading the level of evidence include 1) dose-response gradient, 2) large magnitude of effect, and 3) bias in studies that could have underestimated the demonstrated effect. These factors are described in more details in Table 2. Generally, the rating could rise or fall by one level for each factor. Nevertheless, downgrading two levels because of one factor is also possible if the factor is significant enough to severely affect the quality of the body of evidence. Downgrading one level because of the presence of two factors is also possible if one factor is not significant enough to downgrade one level. The overall grading determined by the two reviewers was further reviewed by the co-author (EY) using the same criteria and procedure. 


\section{$\underline{\text { Put Tables } 1 \& 2 \text { about here }}$}

\section{RESULTS}

\section{Papers selected for review}

More than 900 published papers were initially identified (LIST of papers) using the keywords through the different database system. From this LIST, 13 journal papers that were potentially relevant at the level of abstract were selected by the two reviewers as the SET of papers for review (see Table 3). After reading the full-text article, one reviewer selected nine papers while the other selected ten papers for consideration to be included in the CORE papers. With the agreement on the nine papers to be selected and three papers not to be selected, the inter-rater reliability (agreement) in identifying the CORE papers was $92.3 \%$ $([9+3] / 13)$. The disagreement was resolved by discussion and a consensus was reached on selecting nine CORE papers, which provide information on the treatment effects of resonant voice therapy or immediate effects of resonant voice were finally included (see Table 3 papers marked with asterisk). The four papers that were not selected were either nonexperimental reviews of resonant voice therapy (Roy, 2008; Schneider \& Sataloff, 2007; Ziegler, Gillespie, \& Verdolini Abbott, 2010), or used resonant voice as as one of the components of their therapy regime (Schindler, et al., 2008). The selection process is outlined in Figure 1. The different types of resonant voice techniques described in these nine papers are summarized and reviewed in the following sections.

Put Figure 1 and Table 3 about here 


\section{Description of resonant voice therapy}

Resonant voice therapy is a neuromuscular training approach that aims at training individuals with voice disorders to produce voice in a resonant and easy manner (Roy et al, 2003; Verdolini-Marston et al, 1995; Yiu \& Ho, 2002). It facilitates the production of the strongest possible voice with minimal effort (Chen et al, 2007; Verdolini-Marston et al, 1995; Verdolini et al, 1998). When resonant voice is produced correctly, the vocal folds are shown to be barely adducted or barely abducted (Verdolini et al, 1998). This phonatory gesture minimises the impact pressure between the vocal folds (Roy et al, 2003; Stemple et al 2000, Verdolini-Marston et al, 1995) and facilitates wound healing (Verdolini Abbott 2012).

\section{Types of resonant voice therapy}

The techniques to facilitate resonant voice have been described by different researchers using different names. The names used by the different studies reported in the CORE papers include Lessac-Madsen Resonant Voice Therapy (LMRVT; Chen et al 2007; VerdoliniMarston et al, 1995), Humming (Chen, Ma \& Yiu, 2014; Ogawa et al, 2013, 2014; Yiu \& Ho, 2002), Stemple's Resonance Therapy reported by Roy et al, (2003), and Lessac's Y-Buzz (Barrichelo \& Behlau, 2007). These four types of resonant voice therapy will be described below.

LMRVT, Humming, Stemple's Resonance Therapy and Y-Buzz share similar basic training procedures. They direct learners' attention to vibratory sensations in facial areas that provide proprioceptive feedback and employ a stepwise hierarchy of practices. There are, however, some procedural differences among the four therapies. LMRVT allows an individual to discover the production of resonance through a series of stretching and vocal exercises, while Humming, Stemple's Resonance Therapy and Y-Buzz techniques introduce the concept of 
resonance through formal exploratory stages. LMRVT does not specify the pitch to be used in the practice, but Stemple's Resonance Therapy, Humming and Y-Buzz involve assigning a comfortable pitch for practice. LMRVT and Stemple's Resonance Therapy allow the client to chant on musical notes but the Humming and Y-Buzz techniques do not rely on the musical concept. Detailed instructional procedures for each of these techniques are given in Tables 4 to 7 .

Put Tables 4-7 about here

\section{Effects of resonant voice therapy}

\section{$\underline{\text { Long-term effectiveness }}$}

From the CORE papers, there were five papers identified that reported the long-term effectiveness of resonant voice therapy. A summary of the review is listed in Table 8. Among these five studies, there were three uncontrolled cohort studies and two randomised controlled trials. All of them showed positive outcomes followed resonant voice therapy despite a number of limitations in their methodological designs.

Put Table 8 about here

Uncontrolled studies Chen, Ma and Yiu (2014) investigated the effects of resonant voice training, using humming, on facial bone vibration. Twelve non-dysphonic normal individuals were recruited and were given four sessions of resonant voice therapy within a week (Chen, Ma \& Yiu, 2014). The participants were asked to produce nasal consonant /m/ and vowels $/ \mathrm{a} /, / \mathrm{i} /, / \mathrm{u} /$ before and after the resonant voice training. The level of vibration on the face (nasal bridge and upper lip) and around the perilaryngeal area were compared using 
piezoelectric accelerometers (Chen et al., 2014). Two-way repeated Analysis of Variance (ANOVA) showed there was a significant main effect of training on facial bone vibration $(\mathrm{p}<$ 0.0001), but not in the perilaryngeal area (Chen et al., 2014). This showed that the increased vibration in facial region was not due to increased energy emitted by the larynx but from the effect of resonant voice therapy training on the facial bone vibration (Chen et al., 2014). This increased bone vibration reflects the extent of resonant voice and could therefore be considered as a feedback indicator for resonant voice. Given that there were only four sessions of therapy given and the effects of the therapy were demonstrated in a group of healthy subjects in whom there might have been ceiling effect in voice production, the level of evidence deserves an upgrade.

Another uncontrolled clinical study conducted by Chen et al. (2007) investigated the effects of resonant voice therapy (LMRVT) on 24 female teachers with voice disorders using perceptual, physiological, acoustic, aerodynamic and functional measures. The participants had one 90-minute treatment session per week for eight weeks (Chen et al., 2007). Paired t tests were used to compare the results before and after the treatment. It was found that the severity of auditory-perceptual ratings (roughness, strain, monotone resonance, hard attack, glottal fry and vocal fatigue); acoustic measures (speaking fundamental frequency and maximum range of speaking intensity); laryngo-stroboscopic findings (vocal fold pathology, mucosal wave and amplitude, and vocal fold closure); phonation threshold pressure, all improved significantly $(\mathrm{p}<0.05)$ following therapy. A number of methodological issues negatively affected the level of evidence. This study was an observational study with no control group and small sample size $(\mathrm{N}=24)$. The study also did not control for blinding of participants. There was also alpha inflation in calculating the statistics for more than 12 outcome measures. 
The third uncontrolled study was reported by Yiu and Ho (2002), in which they investigated the therapeutic effects of humming on the vocal quality of 16 subjects (eight with dysphonia and eight with normal voice) after two sessions of humming practices. Significant improvement was found in auditory-perceptual roughness in both the dysphonic and nondysphonic group $(p=0.02)$. However, the acoustic measures did not show any significant improvement ( $p>0.05)$ (Yiu \& Ho, 2002). Despite the small sample size $(\mathrm{N}=16)$, the positive effect demonstrated just within two sessions of practice pointed to the effectiveness of this technique.

\section{Randomised control trial}

Roy et al. (2003) conducted a randomised clinical trial to compare three treatment programs: amplifier, Stemple's Resonance Therapy, and respiratory muscle training. A total of 64 teachers with voice disorders were randomly assigned into one of these three treatment groups. The groups that used the voice amplifier and Resonance Therapy showed significant pre-post-therapy improvement on the Voice Handicap Index (VHI; Jacobson et al, 1997) score and on self-perceived voice severity (Roy et al, 2003). A number of issues in methodological design lowered the level of evidence of this study. For example, there were a disproportionate number of dropouts in the Resonance Therapy group (11, when compared to four and seven dropouts from the voice amplifier group and respiratory muscle training groups, respectively), and participants and assessors were not blind to the procedures. Nonetheless, these negative factors were balanced by a number of positive factors and the overall level of evidence remained stable. These positive factors included the positive therapy effect despite a relatively high attrition rate, fewer therapy sessions than originally planned, and also the therapists were general speech pathology practitioners who were not dealing with patients with voice disorders on a day-to- 
day basis. The reviewers of the present study considered them as generalists rather than voice experts (Roy et al, 2003).

\begin{abstract}
Another randomised controlled trail was reported by Verdolini-Marston et al (1995). They compared the effects of Lessac-Madsen Resonant Voice Therapy (LMRVT) and Confidential Voice Therapy on women with laryngeal nodules using auditory perceptual and phonatory effort measurements. Significant improvements $(p<0.05)$ were found in the LMRVT group $(\mathrm{N}=3)$ and also in the Confidential Voice Therapy group $(\mathrm{N}=5)$ but not in the control group with vocal hygiene given $(\mathrm{N}=5)$. The study also found better compliance led to better outcomes, regardless of therapy type. The sample size was admittedly small, and there was also a high attrition rate, with three out of six participants in the resonant voice therapy groups who dropped out of from the study. Despite these, the small sample size still demonstrated a positive outcome and this warrants an upgrade of the evidence.
\end{abstract}

$\underline{\text { Immediate effects }}$

Four studies were identified that reported the immediate effects of resonant voice. They are all uncontrolled studies and they are summarized in Table 9.

Put Table 9 about here

Barrichelo and Behlau (2007) conducted an uncontrolled longitudinal study to investigate the resonant voice technique based on Lessac's Y-Buzz using perceptual and acoustic outcome measures. Nine newly graduated actors were recruited as participants. Productions of Y-Buzz and habitual voice using /i/ were compared using auditory-perceptual and acoustic evaluations (Barrichelo \& Behlau, 2007). Y-Buzz productions of /i/were perceived as more 
resonant $74 \%$ of the time when compared with /i/ productions with habitual voice. There were also significant reductions in acoustic jitter $(p=0.002)$ and shimmer $(p=0.038)$ following Y-buzz training. The study design was, however, limited by the small sample size $(\mathrm{N}=9)$. Furthermore, the subjects were allowed to repeat the Y-Buzz productions until they were satisfied with the resonant effect (Barrichelo \& Behlau, 2007). This factor might have introduced a bias in the measurements.

Ogawa et al. (2013) reported a cohort study that investigated the immediate effects of humming on supraglottic compression in 23 subjects with muscle tension dysphonia (MTD). Laryngoscopic evaluations of false vocal fold (FVF) and antero-posterior (AP) compression were compared among natural phonation, humming phonation and um-hum phonation (Ogawa et al, 2013). The study found that humming phonation demonstrated significantly less FVF and AP compression than pre-humming therapy phonation $(\mathrm{p}<0.05)$. In another investigation, Ogawa et al. (2014) reported their findings on another group of subjects (28 with dysphonia, 20 without dysphonia) using electroglottographic (EGG) measures. Perturbation, closed quotient (CQ), and vocal fold contact duration extracted from the electroglottographic (EGG) signals were compared across natural, humming and um-hum phonations (Ogawa et al., 2014). Data from seven of the 28 subjects with dysphonia were excluded from the analysis as they did not produce a major reduction in roughness (less than 1-scale point) using humming or um-hum. A two-way repeated ANOVA showed that the variability (in terms of standard deviation) of CQ and perturbation decreased following humming and um-hum in both the dysphonic and non-dysphonic groups $(\mathrm{p}<0.05)$ (Ogawa et al, 2014). Nevertheless, the exclusion of the outliers in the analysis might have resulted in an attrition bias and inflated the effectiveness. 
Verdolini et al. (1998) conducted a cohort study using videostroboscopy to examine laryngeal adduction in resonant voice. Twelve vocally trained singers or actors were recruited. Six of them were healthy with normal voice and six of them had vocal nodules. They were asked to produce resonant, pressed, normal and breathy voices under video-laryngo-stroboscopy (Verdolini et al, 1998). Blinded visual-perceptual ratings using an ordinal scale were made on the degree of laryngeal adductions. Both the dysphonic and non-dysphonic groups produced resonant voice with barely adducted or abducted laryngeal configuration that was significantly distinctive from those of pressed and breathy voices. The authors admitted that the presence of the endoscopy during the phonation could have confounded the laryngeal configurations (Verdolini et al, 1998). Furthermore, the recruited subjects were all vocally trained singers or actors. This makes it difficult to generalize the results to a general population.

\section{Level of evidence}

Table 10 lists the factors that were considered by the reviewers for each study to evaluate the overall level of evidence of resonant voice therapy. Among the nine studies, seven (77.8\%) were observational or cohort studies and two were randomised clinical trial. Level of evidence was graded by the two reviewers as "low" initially based on the methodological designs in these studies. After discussing with the third reviewer (EY), and reconsidered the designs and also the outcomes of the studies, they reached a consensus that the initial overall level of evidence should be graded as "moderate".

\footnotetext{
A number of methodological limitations were prevalent across these studies. These include a lack of blinding of participants, which was found in all studies (100\%). Overall risk of bias across studies was high, with indirectness of evidence (difference between desired outcome and measured outcome) found in five studies (55.5\%), restricted population (gender,
} 
occupation, vocally trained) in five studies (55.5\%), risk of attrition bias found in four studies (44.4\%), and the risk of co-intervention effect found in one study (11.1\%). Thus, there is a limitation in generalising the findings to a wider population such as different age, gender and occupational groups. None of these studies showed any publication bias or result imprecision and inconsistency. Therefore, reviewers agreed the overall evidence should be downgraded by one level.

Factors that could be considered for upgrading were then considered. There was no dose response gradient found. Bias that might have underestimated the demonstrated effects was, however, noticed in three studies (33.3\%). The overall evidence was therefore upgraded one level. During the grading process, the two reviewers agreed on the downgrade factor "study limitations" and the upgrade factor "bias underestimating demonstrated effect". There was an initial disagreement on the presence of the "indirectness of evidence" factor. After discussion, consensus was reached and both reviewers agreed on the presence of this "indirectness of evidence" factor. The third reviewer agreed with the two reviewers on all the downgrading and upgrading evaluation. With the downgrade and upgrade cancelling each other, all three reviewers agreed the final overall level of evidence of resonant voice therapy in treating vocal pathology should be graded as "moderate".

Put Table 10 about here

\section{DISCUSSION}

A review of the nine studies found a consistent result that resonant voice therapy brought about changes in perceptual voice quality and overall efficiency of production. However, 
some of these changes cannot be confidently attributed to resonant voice training per se, as many of these studies did not include a control group for comparison. Overall, the grading of effectiveness of resonant voice therapy based on current available literature is "moderate" as the upgrading factors nullified the downgrading factors. There is thus a moderate level of confidence in the effectiveness of resonant voice therapy in treating vocal pathology.

This review clearly shows that the literature only has a limited number of high-quality studies and therefore could only provide a moderate level of evidence to support the effectiveness of resonant voice therapy in treating voice problems. Indeed, this observation could well be applied equally to other similar voice treatment techniques. Hence, there is a need to develop further high-quality clinical studies to provide more evidence to determine the effectiveness of resonant voice therapy. Most of the studies reviewed were observational in nature without the inclusion of control groups for comparison. Hence, more randomised controlled studies are needed to produce a higher level of evidence. A majority of the studies reviewed were based on a small sample size. Larger sample size using power statistics to assist in estimating the needed sample size would be essential. Attrition rate should also be taken into consideration in determining the sample size. The present review also found that most studies were restricted to a narrow population, by including only one gender (Chen et al, 2007; Verdolini-Marston et al, 1995), specific occupational groups (Barrichelo \& Behlau, 2007; Roy et al 2003) or vocally trained participants (Verdolini et al, 1998). Multicentre trials will also be needed to determine whether these therapy types are effective for different populations and different age groups, and whether they are effective when conducted by different clinicians. Dysphonic populations should continue to be the focus for future studies of resonant voice therapy. This is essential, as the findings will need to show that the effects of resonant voice therapy are not restricted to a specific gender, occupation or vocally trained 
individuals. The present review also found that more randomised controlled trials with a stringent methodological design such as blinding of participants and assessors should be conducted so that performance and assessment biases can be reduced or eliminated. In summary, available data showed that resonant voice therapy has a moderate level of evidence to support its use in clinical practice. Nevertheless, with the limitations in the methodology used in these studies, researchers and clinicians who are interested in the effectiveness of resonant voice therapy should carry out more randomised controlled studies with a larger sample size of sufficient power and specifically defined population groups.

\section{REFERENCES}

Barrichelo, V.M., Behlau, M. (2007). Perceptual identification and acoustic measures of the resonant voice based on 'Lessac's Y-Buzz'”- a preliminary study with actors. Journal of Voice, 21(1), 46-53.

Barton, M. B., Miller, T., Wolff, T., Petitti, D., LeFevre, M., Sawaya, G., Yawn, B., GuirguisBlake, J., Calonge, N. \& Harris, R. (2007). How to read the new recommendation statement: methods update from the US Preventive Services Task Force. Annals of Internal Medicine, 147(2), 123-127.

Boone, D. R., McFarlane, S. C., \& Von Berg, S. (2005). The voice and voice therapy $\left(7^{\text {th }}\right.$ ed.). Boston: Allyn \& Bacon.

Chen, F. C., Ma, E. P. M., \& Yiu, E. M. L. (2014). Facial Bone Vibration In Resonant Voice Production. Journal of Voice, 28(5), 596-602.

Chen, S.H., Hsiao, T.Y., Hsiao, L.C., Chung, Y.M., Chiang, S.C. (2007). Outcome of resonant voice therapy for female teachers with voice disorders: perceptual, 
physiological, acoustic, aerodynamic, and functional measurements. Journal of Voice. $21(4), 415-425$.

Colton, R., Casper, J. K., \& Leonard, R. (2006). Understanding voice problems: A physiological perspective for diagnosis and treatment (3rd ed.). Baltimore: William \& Wilkins.

Ebell, M. H., Siwek, J., Weiss, B. D., Woolf, S. H., Susman, J., Ewigman, B., \& Bowman, M. (2004). Strength of recommendation taxonomy (SORT): a patient-centered approach to grading evidence in the medical literature. The Journal of the American Board of Family Practice, 17(1), 59-67.

Guzman, M., Laukkanen, A. M., Krupa, P., Horacek, J., Svec, J. G., \& Geneid, A. (2013). Vocal tract and glottal function during and after vocal exercising with resonance tube and straw. J Voice, 27(4), 523 e519-534.

Higgins, J. P .T. \& Green, S. (2011). Cochrane Handbook for Systematic Reviews of Interventions Version 5.1.0. The Cochrane Collaboration. Retrieved January, 2, 2015. from www.cochrane-handbook.org.

Jacobson, B. J., Johnson, A., Grywalski, C., Silbergleit, A., Jacobson, G., Benninger, M. S., et al. (1997). The Voice Handicap Index (VHI): Development and validation. American Journal of Speech-Language Pathology, 6(3), 66-70.

Lessac, A. (1997). The Use and Training of the Human Voice: A Practical Approach to Speech and Voice Dynamics. $3^{\text {rd }}$ ed. New York: Mayfield Publishing Company.

Moher D, Liberati A, Tetzlaff J, Altman DG, The PRISMA Group (2009). Preferred Reporting Items for Systematic Reviews and Meta-Analyses: The PRISMA Statement. BMJ, 339:b2535. 
Ogawa, M., Hosokawa, K., Yoshida, M., Yoshii, T., Shiromoto, O., \& Inohara, H. (2013). Immediate effectiveness of humming on the supraglottic compression in subjects with muscle tension dysphonia. Folia Phoniatrica et Logopaedica, 65(3), 123-128.

Ogawa, M., Hosokawa, K., Yoshida, M., Iwahashi, T, Hashimoto, M \& Inohara, H. (2014). Immediate effects of humming on computed electroglottographic parameters in patients with muscle tension dysphonia, Journal of Voice, 28(6), 733-741.

Orbelo, D. M., Li, N. Y.-K., \& Verdolini Abbott, K. (2014). Lessac-Madsen Resonant Voice Therapy in the Treatment of Secondary MTD. In J. C. Stemple \& E. R. Hapner (Eds.), Voice Therapy: Clinical Case Studies. San Diego: Plural Publishing.

Peterson, K. L., Verdolini-Marston, K., Barkmeier, J. M., \& Hoffman, H. T. (1994). Comparison of aerodynamic and electroglottographic parameters in evaluating clinically relevant voicing patterns. Annals of Otology, Rhinology and Laryngology, $103,335-346$

Roy, N. (2008). Assessment and treatment of musculoskeletal tension in hyperfunctional voice disorders. International Journal of Speech-Language Pathology, 10(4), 195-209.

Roy, N., Weinrich, B., Gray, S.D., Tanner, K., Stemple, J.C., Sapienza, C.M. (2003). Three treatments for teachers with voice disorders: a randomized clinical trial. Journal of Speech Language Hearing Research, 46 (3), 670-688.

Schindler, A., Bottero, A., Capaccio, P., Ginocchio, D., Adorni, F., \& Ottavianai, F. (2008). Vocal improvement after voice therapy in unilateral vocal fold paralysis. Journal of Voice, 22(1), 113-118.

Schneider, S.L. \& Sataloff, R.T. (2007). Voice therapy for the professional voice. Otolaryngologic Clinics of North America, 40(5), 1133-1149. 
Schünemann, H., Brożek, J., Guyatt, G., \& Oxman, A. (2013) GRADE Handbook for Grading Quality of Evidence and Strength of Recommendations. The GRADE Working Group. Retrieved January 1, 2015, from www.guidelinedevelopment.org/handbook.

Schulz, K. F., Altman, D. G., \& Moher, D. (2010). CONSORT 2010 statement: updated guidelines for reporting parallel group randomised trials. BMC Medicine, 8(1), 18.

Stemple, J.C., Glaze, L.E., Klaben, B.G. (2000). Clinical Voice Pathology: Theory and Management. 3rd ed. San Diego, CA: Singular Publishing Group.

Titze, I.R. (2001). Acoustic Interpretation of Resonant Voice. Journal of Voice, 15 (4), 519528.

Titze, I.R. (2006). Voice Training and Therapy With a Semi-Occluded Vocal Tract: Rationale and Scientific Underpinning, Journal of Speech, Language, and Hearing Research, 49 (2), 448-459.

Verdolini, K. (2000). Case Study: Resonant Voice Therapy. In J. Stemple, Voice therapy: Clinical Studies (2 ${ }^{\text {nd }}$ ed., pp.46-62). San Diego: Singular Publishing Group.

Verdolini, K., Druker, D.G., Palmer, P.M., Samawi, H. (1998). Laryngeal adduction in resonant voice. Journal of Voice, 12(3), 315-327.

Verdolini Abbott, K. (2008) Lessac-Madsen Resonant Voice Therapy: Clinician Manual. San Diego: Plural Publishing.

Verdolini Abbott, K., Li, N. Y. K., Branski, R. C., Rosen, C. A., Grillo, E. G., Steinhauer, K. \& Hebda, P. A. (2012). Vocal exercise may attenuate acute vocal fold inflammation. Journal of Voice, 26(6), 814. e811-813. 
Verdolini-Marston, K, Burke, M.K., Lessac, A., Glaze, L., Caldwell, E. (1995). Preliminary study of two methods of treatment for laryngeal nodules. Journal of Voice, 9(1), 7485.

Yiu, E.M.-L. \& Ho, E.Y.-Y. (2002) Short-term effect of humming on vocal quality. Asia Pacific Journal of Speech Language Hearing, 7,123-137

Ziegler, A., Gillespie, A.I., \& Verdolini Abbott, K.V. (2010). Behavioural treatment of voice disorder in teachers. Folia Phoniatrica et Logopaedica, 6(1-2), 9-23. 
Figure 1. PRISMA Flow chart (Moher et al, 2009) showing selection process

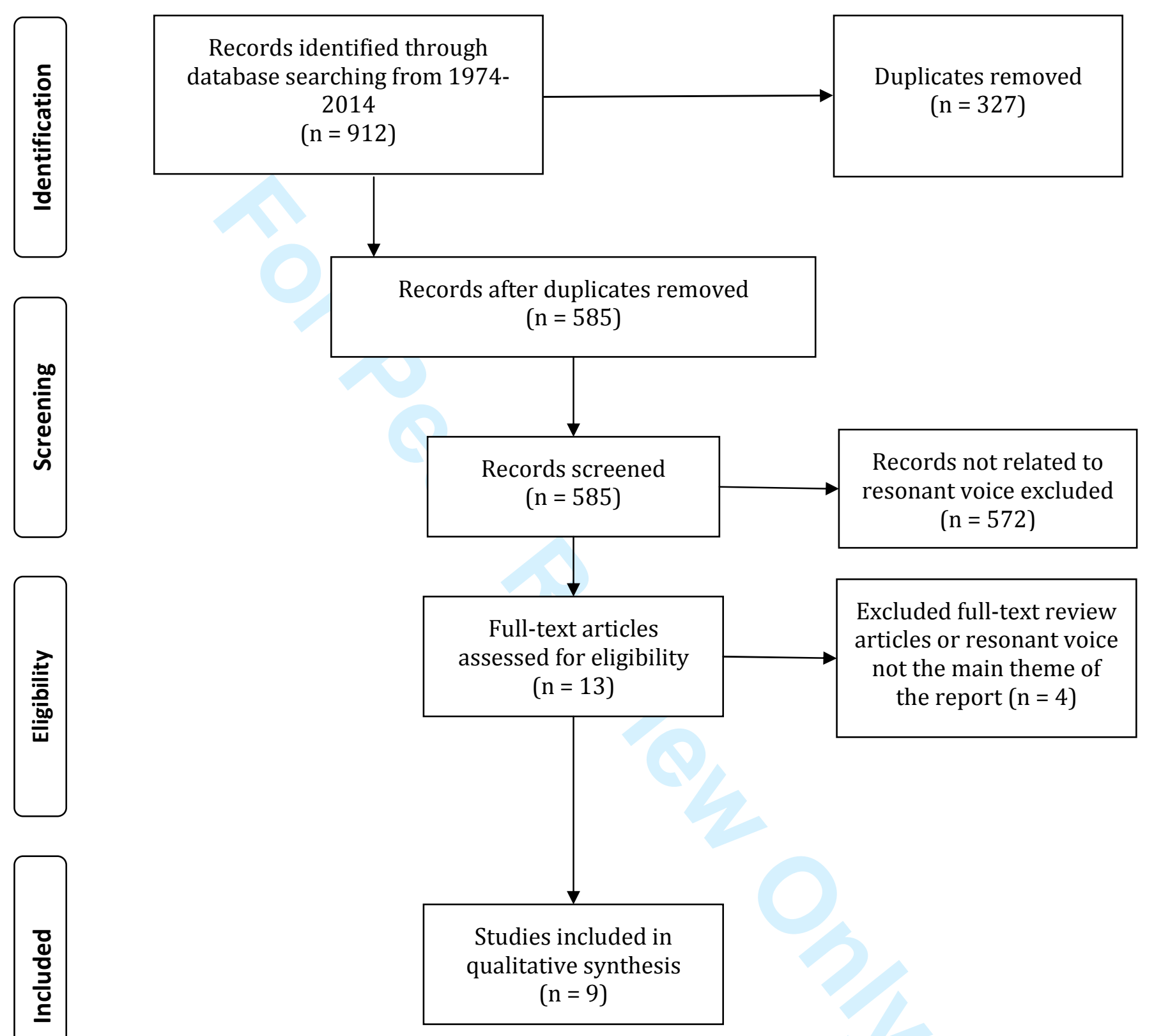


Table 1. Level of quality of evidence according to GRADE (Schünemann et. al, 2013)

\begin{tabular}{ll}
\hline Level of evidence & \multicolumn{1}{c}{ Definition } \\
\hline $\begin{array}{l}\text { High } \\
\text { (Randomised Clinical Trial) }\end{array}$ & $\begin{array}{l}\text { There is much confidence that true effect lies close to } \\
\text { that of the estimate of the effect }\end{array}$ \\
\hline Moderate & $\begin{array}{l}\text { The true effect is likely to be close to the estimate of } \\
\text { the effect, but there is a possibility that it is } \\
\text { substantially different }\end{array}$ \\
\hline $\begin{array}{l}\text { Low } \\
\text { (Observational Studies) }\end{array}$ & \begin{tabular}{l} 
There is limited confidence in the effect estimate \\
\hline Very Low
\end{tabular} \\
& The true effect is likely to be substantially different \\
\hline
\end{tabular}


Table 2. Upgrading and downgrading factors for GRADE rating

\begin{tabular}{|c|c|c|}
\hline Downgrading Factors & & Descriptions \\
\hline \multirow[t]{2}{*}{ 1. Study Limitations } & $\begin{array}{l}\text {-Lack of random } \\
\text { sequence generation }\end{array}$ & $\begin{array}{l}\text { This limitation reduces the likelihood that } \\
\text { comparable groups are produced }\end{array}$ \\
\hline & $\begin{array}{l}\text {-Lack of allocation } \\
\text { concealment }\end{array}$ & $\begin{array}{l}\text { This limitation would introduce } \\
\text { examiners' biases }\end{array}$ \\
\hline \multirow[t]{3}{*}{ 2. Risks of bias } & $\begin{array}{l}\text {-Lack of blinding of } \\
\text { participants and } \\
\text { assessors }\end{array}$ & Risk of performance or assessment bias \\
\hline & -Attrition bias & $\begin{array}{l}\text { Exclusion of participants from reports of } \\
\text { analysis or withdrawal of participants } \\
\text { would create bias }\end{array}$ \\
\hline & $\begin{array}{l}\text {-Selective reporting } \\
\text { of a subset of the } \\
\text { original variables }\end{array}$ & Risk of reporting bias \\
\hline$\frac{\text { 3. Indirectness of }}{\underline{\text { evidence }}}$ & & $\begin{array}{l}\text { Difference between desired outcome } \\
\text { and measured outcome }\end{array}$ \\
\hline$\frac{\text { 4. Unexplained }}{\text { inconsistency of }}$ & $P=$ & $\begin{array}{l}\text { Results across studies are found to be } \\
\text { inconsistent without reasonable } \\
\text { explanation }\end{array}$ \\
\hline$\frac{\text { 5. Imprecision of }}{\underline{\text { result }}}$ & & $\begin{array}{l}\text { Wide confidence intervals imply } \\
\text { uncertainty in the estimate }\end{array}$ \\
\hline 6. Publication bias & & $\begin{array}{l}\text { Publishing only from a number of small } \\
\text { or commercially funded studies may } \\
\text { present biased views }\end{array}$ \\
\hline Upgrading Factors & & Descriptions \\
\hline$\frac{\text { 1. Dose-response }}{\text { gradient }}$ & & $\begin{array}{l}\text { Different levels of exposure of therapy } \\
\text { result in different levels of effectiveness }\end{array}$ \\
\hline 2. Large magnitude of & & $\begin{array}{l}\text { Studies demonstrate at least } 2 \text { times the } \\
\text { magnitude of intervention effect than } \\
\text { other reported studies }\end{array}$ \\
\hline $\begin{array}{l}\text { 3. Biases } \\
\underline{\underline{\text { underestimating a }}} \\
\underline{\text { result }}\end{array}$ & & $\begin{array}{l}\text { Despite possible biases that would } \\
\text { underestimate a result, intervention effect } \\
\text { is still shown }\end{array}$ \\
\hline
\end{tabular}


Table 3. Initial set of $\mathbf{1 3}$ journal papers selected by the two reviewers

\begin{tabular}{|c|c|c|c|}
\hline Authors / Year of publication & Title of the paper & $\begin{array}{l}\text { Journal name/ } \\
\text { pages }\end{array}$ & Therapy name \\
\hline $\begin{array}{l}\text { *Barrichelo, V.M. \& Behlau, M. } \\
\text { (2007) }\end{array}$ & $\begin{array}{l}\text { Perceptual identification and acoustic measures of the resonant } \\
\text { voice based on "Lessac's Y-Buzz'”-a preliminary study with } \\
\text { actors. }\end{array}$ & $\begin{array}{l}\text { Journal of Voice } 21 \text { Observational } \\
(1), 46-53 .\end{array}$ & Lessac's Y-Buzz \\
\hline $\begin{array}{l}\text { *Chen, F. C., Ma, E. P.-M., \& } \\
\text { Yiu, E. M.-L. (2014) }\end{array}$ & Facial Bone Vibration In Resonant Voice Production. & $\begin{array}{l}\text { Journal of } \\
\text { Voice, 28(5), 596- } \\
602 .\end{array}$ & Humming \\
\hline $\begin{array}{l}\text { *Chen, S.H., Hsiao, T.Y., Hsiao, } \\
\text { L.C., Chung, Y.M., \& Chiang, } \\
\text { S.C. (2007) }\end{array}$ & $\begin{array}{l}\text { Outcome of resonant voice therapy for female teachers with } \\
\text { voice disorders: perceptual, physiological, acoustic, } \\
\text { aerodynamic, and functional measurements. }\end{array}$ & $\begin{array}{l}\text { Journal of Voice. } 21 \text { Observational } \\
\text { (4) } 415-425\end{array}$ & $\begin{array}{l}\text { Lessac-Madsen } \\
\text { Resonant Voice } \\
\text { Therapy }\end{array}$ \\
\hline $\begin{array}{l}\text { *Ogawa, M., Hosokawa, K., } \\
\text { Yoshida, M., Yoshii, T., } \\
\text { Shiromoto, O., \& Inohara, H. } \\
(2013)\end{array}$ & $\begin{array}{l}\text { Immediate effectiveness of humming on the supraglottic } \\
\text { compression in subjects with muscle tension dysphonia. }\end{array}$ & $\begin{array}{l}\text { Folia Phoniatrica Et Observational } \\
\text { Logopaedica, } 65(3), \\
123-128 .\end{array}$ & Humming \\
\hline $\begin{array}{l}\text { *Ogawa, M., Hosokawa, K., } \\
\text { Yoshida, M., Iwahashi, T, } \\
\text { Hashimoto, M \& Inohara, H. } \\
(2014) .\end{array}$ & $\begin{array}{l}\text { Electroglottographic Parameters in Patients With Muscle } \\
\text { Tension Dysphonia. }\end{array}$ & Journal of Voice, 1-9 Observational & Humming \\
\hline $\begin{array}{l}\text { *Roy, N., Weinrich, B., Gray, } \\
\text { S.D., Tanner, K., Stemple, J.C., } \\
\text { \& Sapienza, C.M. (2003) }\end{array}$ & $\begin{array}{l}\text { Three treatments for teachers with voice disorders: a } \\
\text { randomized clinical trial. }\end{array}$ & $\begin{array}{l}\text { Journal of Speech } \\
\text { Language Hearing } \\
\text { Research, } 46(3), \\
670-688 .\end{array}$ & $\begin{array}{l}\text { Stemple's } \\
\text { Resonance } \\
\text { Therapy }\end{array}$ \\
\hline
\end{tabular}


Table 3 (con't). Initial set of 13 journal papers selected by the two reviewers

\begin{tabular}{|c|c|c|c|c|}
\hline Roy, N. (2008) & $\begin{array}{l}\text { Assessment and treatment of musculoskeletal tension in } \\
\text { hyperfunctional voice disorders. }\end{array}$ & $\begin{array}{l}\text { International Journal } \\
\text { of Speech-Language } \\
\text { Pathology, 10(4), 195- } \\
209 .\end{array}$ & $\begin{array}{l}\text { Non- } \\
\text { experimental } \\
\text { review }\end{array}$ & $\begin{array}{l}\text { Resonant Voice } \\
\text { Therapy }\end{array}$ \\
\hline $\begin{array}{l}\text { Schindler, A., Bottero, A., } \\
\text { Capaccio, P., Ginocchio, D., } \\
\text { Adorni, F., \& Ottaviani, F. } \\
(2008)\end{array}$ & $\begin{array}{l}\text { Vocal improvement after voice therapy in unilateral vocal fold } \\
\text { paralysis. }\end{array}$ & $\begin{array}{l}\text { Journal of } \\
\text { Voice, 22(1), 113- } \\
118 .\end{array}$ & Observational & $\begin{array}{l}\text { Humming/ } \\
\text { resonant voice }\end{array}$ \\
\hline $\begin{array}{l}\text { Schneider, S.L., \& Sataloff, R.T. } \\
\text { (2007) }\end{array}$ & Voice therapy for the professional voice & $\begin{array}{l}\text { Otolaryngologic } \\
\text { Clinics of North } \\
\text { America, } 40(5), \\
1133-1149 .\end{array}$ & $\begin{array}{l}\text { Non- } \\
\text { experimental } \\
\text { review }\end{array}$ & $\begin{array}{l}\text { Resonance } \\
\text { exercise/ } \\
\text { Buzz }\end{array}$ \\
\hline $\begin{array}{l}\text { *Verdolini-Marston, K., Burke, } \\
\text { M.K., Lessac, A., Glaze, L., \& } \\
\text { Caldwell, E. (1995) }\end{array}$ & $\begin{array}{l}\text { Preliminary study of two methods of treatment for laryngeal } \\
\text { nodules }\end{array}$ & $\begin{array}{l}\text { Journal of Voice, } \\
9(1), 74-85 .\end{array}$ & $\begin{array}{l}\text { Randomised } \\
\text { controlled trial }\end{array}$ & $\begin{array}{l}\text { Lessac-Madsen } \\
\text { Resonant Voice } \\
\text { Therapy }\end{array}$ \\
\hline $\begin{array}{l}\text { *Verdolini, K., Druker, D.G., } \\
\text { Palmer, P.M., \& Samawi, H. } \\
\text { (1998) }\end{array}$ & Laryngeal adduction in resonant voice. & $\begin{array}{l}\text { Journal of Voice, } \\
12(3), 315-327 .\end{array}$ & Observational & Resonant Voice \\
\hline $\begin{array}{l}\text { *Yiu, E.M.-L. \& Ho, E.Y.-Y.. } \\
(2002)\end{array}$ & Short-term effect of humming on vocal quality. & $\begin{array}{l}\text { Asia Pacific Journal } \\
\text { of Speech Language } \\
\text { Hearing, 7,123-137 }\end{array}$ & Observational & Humming \\
\hline $\begin{array}{l}\text { Ziegler, A., Gillespie, A.I., \& } \\
\text { Verdolini Abbott, K.V. (2010) }\end{array}$ & Behavioral treatment of voice disorders in teachers. & $\begin{array}{l}\text { Folia Phoniatrica et } \\
\text { Logopaedica, 62(1- } \\
2), 9 .\end{array}$ & $\begin{array}{l}\text { Non- } \\
\text { experimental } \\
\text { review }\end{array}$ & $\begin{array}{l}\text { Resonant Voice } \\
\text { Therapy }\end{array}$ \\
\hline
\end{tabular}

* Studies selected as CORE papers

URL: http:/mc.manuscriptcentral.com/tas| Email: ijs/p.editor@sydney.edu.au 
Table 4. Basic elements of Lessac-Madsen Resonant Voice Training (LMRVT) (Verdolini Abbott, 2008)

1. Stretches: Basic body stretches of chest, shoulders, neck, jaws, lips, tongue, mouth and throat.

2. Resonant Voice Core Exercises:

- /m/ - "mmmmmm" (other voiced continuants are used in subsequent sessions)

- /m/ words

- /m/ phrases

3. Resonant Voice Chant:

-/m/ + vowel sounds, e.g. /mi mi mi mi mi mi/

-nasal + Non-nasal sounds, e.g. / mi mi pi pi mi mi/

(other consonants/vowels are used in subsequent sessions)

-/m/ loaded phrases, e.g. "Meet me Peter, meet me"

4. Resonant Voice Vocal Communicator:

-Conversational speech: "m-hmmm", "really", "right”, “yeah", “no"

5. Resonant Voice Mini:

-Change from old voice to resonant voice

6. Resonant Voice Messa di Voice:

- /m/+ /j/+ vowel, e.g. /mmmjjjiii/, /mmmjjjaaa/,/mmmjjjuuu/ using

crescendo/descrescendo (other consonants/vowels are used in subsequent sessions)

-Words using crescendo/descrescendo

7. Resonant Voice Conversation:

-Conversational in a variety of contexts

8. Own treatment:

- Planning functional goals and practice 
Table 5. Instructional steps for Y-Buzz (Barrichelo \& Behlau, 2007)

1. To produce "shhh" like asking someone to be quiet.

2. To produce "shhh" with a Y-Buzz sound linked to it.

3. To explore the Y-buzz and find a pitch that can result in maximum resonance with minimal effort.

4. To check nasality of Y-buzz not altered by pressing the nostrils together.

5. To continue exploring, improving and refining the tonal and vibrational quality.

6. To practice Y-buzz while gently shaking one hand and to observe how the action enhances pulsation of the Y- buzz sound into the facial bones; then to continue the Y-Buzz without shaking the hand.

7. To produce the Y-Buzz sound like siren sound.

8. To move from practicing Y-Buzz with words, to phrases and natural speech. 
Table 6. Instructional steps for Humming (Yiu \& Ho, 2002)

1. To produce a hum like sincerely acknowledging someone in a relaxed manner.

2. To glide up and down the musical scale to find a comfortable pitch that can result in maximum resonance with minimal effort.

3. To use a finger to feel the resonance of the hum over the area of nasal bridge, and to attend to the feedback given by the clinician.

4. To hum at a comfortable pitch with a sustained vowel at the end of $/ \mathrm{m} /: / \mathrm{m} / \ldots / \mathrm{a} /$.

5. To hum with words, phrases and natural speech. 
Table 7. Instructional steps for Stemple's Resonance Therapy (Stemple, Glaze \& Klaben, 2000)

1. To begin with choosing the appropriate pitch, then to count from " 1 to 5 " and match the pitch to the closest note on a pitch pipe. Then use one note higher on the pitch pipe throughout the training.

2. To produce "Hmm-molm- molm..." as a sigh, then with a forward focus, using adequate abdominal breathing in a relaxed manner (Basic Gesture).

3. Advanced Gesture:

- Stage 1- To produce voiced consonants i.e. "molm-molm..." by varying the rate; then varying the rate and intensity; then to produce with the intonation of spoken phrases; then to chant real voiced phrases on a musical note.

- $\quad$ Stage 2 - To repeat tasks in Stage 1, adding voiceless consonants and voiced consonants. (Stemple, Glaze \& Klaben, 2000).

- $\quad$ Stage 3 - To chant phrases with extra forward focus and exaggerated articulation.

- $\quad$ Stage 4 - To read paragraphs with exaggerated articulation and natural production.

- $\quad$ Step 5 - To generalise to normal conversations.

- $\quad$ Step 6 - To generalise to various environmental settings in daily life.

- $\quad$ Step 7 - To generalise to a variety of emotional contexts. 
Table 8. Studies investigating the long-term effectiveness of resonant voice therapy

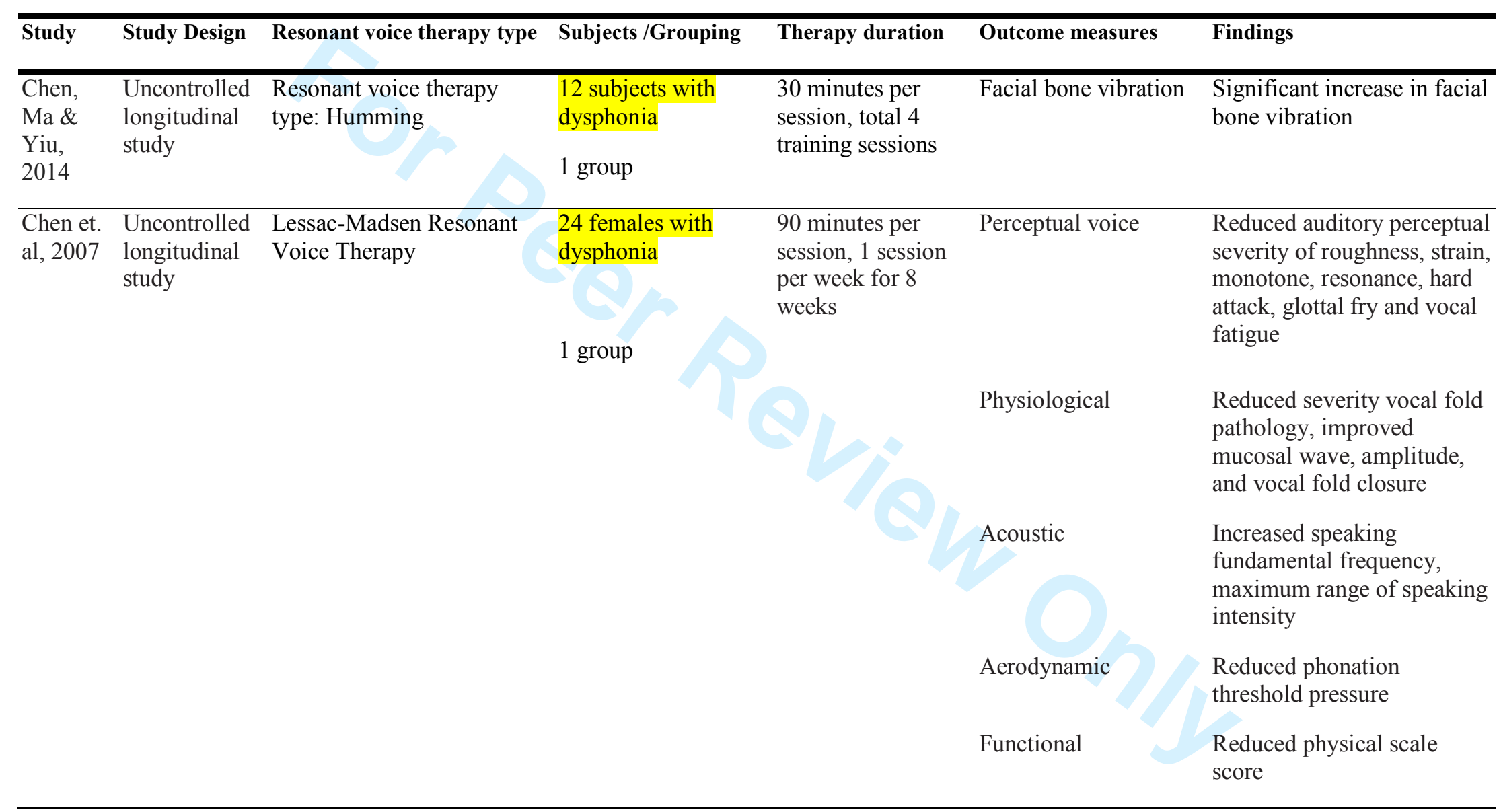

(To be continued) 
Table 8 (con't) Studies investigating the long-term effectiveness of resonant voice therapy

\begin{tabular}{|c|c|c|c|c|c|c|}
\hline Study & Study Design & Resonant voice therapy type & Subjects /Grouping & Therapy duration & Outcome measures & Findings \\
\hline $\begin{array}{l}\text { Roy et. } \\
\text { al, } 2003\end{array}$ & $\begin{array}{l}\text { Randomised } \\
\text { controlled } \\
\text { trial }\end{array}$ & $\begin{array}{l}\text { Stemple's Resonance } \\
\text { Therapy }\end{array}$ & $\begin{array}{l}64 \text { teachers with } \\
\text { dysphonia } \\
3 \text { groups: } \\
\text { 1.Voice amplifier } \\
(\mathrm{N}=25) \\
\text { 2.Resonance Therapy } \\
(\mathrm{N}=19) \\
\text { 3.Respiratory muscle } \\
\text { training }(\mathrm{N}=20)\end{array}$ & $\begin{array}{l}1 \text { session in } 2 \text { weeks, } \\
\text { for } 6 \text { weeks }\end{array}$ & $\begin{array}{l}\text { Voice Handicapped } \\
\text { Index (VHI) \& Voice } \\
\text { Severity Rating }\end{array}$ & $\begin{array}{l}\text { Significant improvements in } \\
\text { VHI scores and voice } \\
\text { severity self-ratings }\end{array}$ \\
\hline $\begin{array}{l}\text { Verdolini } \\
\text {-Marston } \\
\text { et. al., } \\
1995\end{array}$ & $\begin{array}{l}\text { Randomised } \\
\text { controlled } \\
\text { trial }\end{array}$ & $\begin{array}{l}\text { Lessac-Madsen Resonant } \\
\text { Voice Therapy (LMRT) }\end{array}$ & $\begin{array}{l}13 \text { females with } \\
\text { dysphonia } \\
3 \text { groups: } \\
\text { 1.Vocal hygiene \& } \\
\text { LMRT (N=3) } \\
\text { 2.Vocal hygiene \& } \\
\text { Confidential Voice } \\
\text { therapy }(\mathrm{N}=5) \\
\text { 3.Vocal hygiene } \\
\text { (Control): }(\mathrm{N}=5)\end{array}$ & $\begin{array}{l}9 \text { sessions within } 2 \\
\text { weeks }\end{array}$ & $\begin{array}{l}\text { Auditory-perceptual } \\
\text { voice quality } \\
\text { Visual perceptual } \\
\text { (laryngoscopy) } \\
\text { Phonatory effort }\end{array}$ & $\begin{array}{l}\text { Overall improvements in } \\
\text { auditory-perceptual, visual- } \\
\text { perceptual ratings and } \\
\text { phonatory effort measures }\end{array}$ \\
\hline \multirow[t]{2}{*}{$\begin{array}{l}\text { Yiu \& } \\
\text { Ho, } 2002\end{array}$} & $\begin{array}{l}\text { Uncontrolled } \\
\text { cohort }\end{array}$ & Humming & $\begin{array}{l}8 \text { subjects with } \\
\text { hyperfunctional } \\
\text { dysphonia and } 8 \text { with } \\
\text { normal voice }\end{array}$ & $\begin{array}{l}2 \text { sessions, } 45 \\
\text { minutes per session }\end{array}$ & $\begin{array}{l}\text { Auditory-perceptual } \\
\text { voice quality }\end{array}$ & $\begin{array}{l}\text { Significant reduction in } \\
\text { auditory-perceptual } \\
\text { roughness in both dysphonic } \\
\text { and non-dysphonic group }\end{array}$ \\
\hline & & & $\begin{array}{l}2 \text { groups: } \\
\text { Dysphonic vs non- } \\
\text { dysphonic }\end{array}$ & & Acoustic analysis & $\begin{array}{l}\text { No change in acoustic } \\
\text { measures }\end{array}$ \\
\hline
\end{tabular}


Table 9. Studies investigating the immediate effects of resonant voice

\begin{tabular}{|c|c|c|c|c|c|}
\hline Study & Study Design & $\begin{array}{l}\text { Resonant voice therapy } \\
\text { type }\end{array}$ & Subjects/Grouping & Outcome measurement & Findings \\
\hline $\begin{array}{l}\text { Barrichelo } \\
\& \text { Behlau, } \\
2007\end{array}$ & $\begin{array}{l}\text { Uncontrolled } \\
\text { longitudinal } \\
\text { study }\end{array}$ & $\begin{array}{l}\text { Y-Buzz } \\
\text { Repeated measures } \\
\text { Y-Buzz vs } \\
\text { habitual voice }\end{array}$ & $\begin{array}{l}9 \text { newly graduated actors, } \\
\text { ( } 6 \text { males \& } 3 \text { females) }\end{array}$ & $\begin{array}{l}\text {-Auditory-perceptual } \\
\text { evaluation of /i/ } \\
\text {-Acoustic }\end{array}$ & $\begin{array}{l}\text { Perceptual measures: Y- Buzz more } \\
\text { resonant ( } 74 \% \text { of the time) } \\
\text { Y-Buzz demonstrated significant } \\
\text { decrease in acoustic irregularity and } \\
\text { shimmer }\end{array}$ \\
\hline $\begin{array}{l}\text { Ogawa et } \\
\text { al., } 2013\end{array}$ & Cohort & $\begin{array}{l}\text { Humming } \\
\text { Repeated measures: } \\
\text { natural phonation vs } \\
\text { humming phonation vs } \\
\text { um-hum phonation }\end{array}$ & $\begin{array}{l}23 \text { subjects with muscle } \\
\text { tension dysphonia \& } 15 \\
\text { subjects with normal } \\
\text { voice }\end{array}$ & $\begin{array}{l}\text { Supraglottic compression: } \\
\text {-false vocal fold } \\
\text {-anterior-posterior indices }\end{array}$ & $\begin{array}{l}\text { Significant reduction in false vocal } \\
\text { fold and antero-posterior compression } \\
\text { in both subject groups using humming }\end{array}$ \\
\hline $\begin{array}{l}\text { Ogawa et. } \\
\text { al, } 2014\end{array}$ & Cohort & $\begin{array}{l}\text { Humming } \\
\text { Repeated measures: } \\
\text { natural phonation vs } \\
\text { humming phonation vs } \\
\text { um-hum phonation }\end{array}$ & $\begin{array}{l}21 \text { subjects with muscle } \\
\text { tension dysphonia \& } 20 \\
\text { subjects with normal } \\
\text { voice }\end{array}$ & $\begin{array}{l}\text { Electroglottographic } \\
\text { signals: } \\
\text {-Perturbation parameters } \\
\text {-Contact quotient }\end{array}$ & $\begin{array}{l}\text { Significantly lower variability in the } \\
\text { perturbation and contact quotient } \\
\text { during humming and um-hum in both } \\
\text { subject groups }\end{array}$ \\
\hline $\begin{array}{l}\text { Verdolini et } \\
\text { al., } 1998\end{array}$ & Cohort & $\begin{array}{l}\text { Resonant voice } \\
\text { Repeated measures: } \\
\text { resonant vs } \\
\text { pressed vs } \\
\text { normal vs } \\
\text { breathy voice }\end{array}$ & $\begin{array}{l}12 \text { vocally rained singers } \\
\text { or actors ( } 6 \text { with laryngeal } \\
\text { nodules, } 6 \text { with normal } \\
\text { voice) }\end{array}$ & $\begin{array}{l}\text { Videostrobscopy: Ordinal } \\
\text { visual-perceptual ratings }\end{array}$ & $\begin{array}{l}\text { Resonant voice was distinctive from } \\
\text { configurations for pressed and breathy } \\
\text { voice }\end{array}$ \\
\hline
\end{tabular}

URL: http:/mc.manuscriptcentral.com/tas| Email: ijslp.editor@sydney.edu.au 
Table 10. Factors determining/affecting the level of evidence of resonant voice therapy studies

\begin{tabular}{|c|c|c|}
\hline Study & Factors that lowered the quality of evidence & Factors that raised the quality of evidence \\
\hline $\begin{array}{l}\text { Chen, Ma \& Yiu, } \\
2014\end{array}$ & $\begin{array}{l}\bullet \text { Small sample size } \\
\bullet \text { No blinding of participants }\end{array}$ & -Demonstrated intervention effect even with limited number of sessions \\
\hline Chen et. al, 2007 & $\begin{array}{l}\bullet \text { Small sample size } \\
\bullet \text { No blinding of participants } \\
\bullet \text { Low generalizability to a wider population }\end{array}$ & \\
\hline Roy et. al, 2003 & $\begin{array}{l}\text { - No blinding of participants and assessors } \\
\text { - Risk of attrition bias (Disproportionate number of dropout in } \\
\text { resonant voice therapy group) } \\
\text { - Low generalizability to a wider population }\end{array}$ & $\begin{array}{l}\text {-Demonstrated intervention effect even with low compliance } \\
\text {-Demonstrated intervention effect even with non-expert therapists } \\
\text {-Demonstrated intervention effect even with limited number of sessions }\end{array}$ \\
\hline \begin{tabular}{|l|} 
Verdolini-Marston \\
et. al., 1995
\end{tabular} & $\begin{array}{l}\bullet \text { Small sample size and no blinding of participants } \\
\bullet \text { Risk of attrition bias } \\
\text { - Risk of co-intervention effect } \\
\text { - Low generalizability to a wider population }\end{array}$ & $\begin{array}{l}\bullet \text { Demonstrated intervention effect even with only } 3 \text { subjects } \\
\text {-Demonstrated intervention effect even within } 2 \text { weeks }\end{array}$ \\
\hline Yiu \& Ho, 2002 & $\begin{array}{l}\bullet \text { Small Sample size } \\
\bullet \text { No blinding of participants }\end{array}$ & -Demonstrated intervention effect even with two sessions \\
\hline $\begin{array}{l}\text { Barrichelo \& } \\
\text { Behlau, } 2007\end{array}$ & $\begin{array}{l}\text { - Small sample size and no blinding of participants } \\
\text { - Indirectness of evidence } \\
\text { - Post-treatment performance measures were selective } \\
\text { - Low generalizability to a wider population }\end{array}$ & \\
\hline Ogawa et. al., 2013 & $\begin{array}{l}\bullet \text { No blinding of participants } \\
\bullet \text { Risk of attrition bias }\end{array}$ & \\
\hline Ogawa et. al., 2014 & $\begin{array}{l}\bullet \text { No blinding of participants } \\
\bullet \text { Risk of attrition bias (subjects without making changes were } \\
\text { excluded from the analysis) }\end{array}$ & \\
\hline $\begin{array}{l}\text { Verdolini et. al., } \\
1998\end{array}$ & $\begin{array}{l}\text { - No blinding of participants } \\
\text { - Low generalizability from vocally trained to wider population } \\
\text { - Rigid endoscopy may affect result }\end{array}$ & \\
\hline
\end{tabular}

URL: http:/mc.manuscriptcentral.com/tasl Email: ijslp.editor@sydney.edu.au 